\title{
Editorial
}

\section{Clinical Databases and the QUEST Initiative}

\author{
Kitty J. Jager ${ }^{\mathrm{a}}$ Carmine Zoccali ${ }^{\mathrm{b}}$ \\ aERA-EDTA Registry, Department of Medical Informatics, Academic Medical Center, University of Amsterdam, \\ Amsterdam, The Netherlands, ${ }^{b}$ CNR-IBIM Clinical Epidemiology and Pathophysiology of Renal Diseases and \\ Hypertension, Renal and Transplantation Unit, Ospedali Riuniti, Reggio Cal, Italy
}

In this issue, Richards et al. [1] provide the results of an assessment of the implementation of clinical practice guidelines in Fresenius Medical Care centres across four European countries. The data collected included performance indicators on haemodialysis adequacy, biocompatibility, anaemia control and phosphate control. The authors showed that after the official adoption of the European Best Practice Guidelines (EBPG) [2,3] within the Fresenius clinics network, the adherence to some of the guidelines improved. For their analyses the authors used data that were derived through the $\mathrm{EuCliD}^{\circledR}$ database, which comprises a part of the Continuous Quality Improvement management system of Fresenius dialysis units [4]. In essence, EuCliD ${ }^{\circledR}$ is a medical registry that receives its data by means of interfaces with existing local data management systems or by local manual data entry. In return, all centres receive benchmark reports that allow them to identify their potential areas of low performance relative to other centres and to act accordingly.

The example provided by Richards et al. shows how knowledge on clinical processes may be used for the assessment and improvement of quality of RRT care. Otherwise, a number of years after the production of clinical practice guidelines such as EBPG and KDOQI, little is known about the adherence to such guidelines outside the setting of studies like the Dialysis Outcomes and Practice Patterns (DOPPS). However, where Fresenius and other companies [5] have realized such collection of clinical performance indicators for the purpose of benchmarking within the setting of their clinics' network, many national and regional renal registries are engaged in similar initiatives. The UK Renal Registry has been quite successful in this regard. Their annual report continues to show statistically significant differences in the achievement of treatment goals between centres that are not readily explained through case-mix and other factors [6]. Many other renal registries, however, experience considerable problems in the production of clinical registry databases allowing such comparisons. A huge problem is posed by the process of data collection, which in some countries still makes use of paper data collection forms or other labour-intensive methods. Another problem comprises the lack of standardization of methods to determine the variables to be collected.

Since two years, renal registries have joined forces to address these problems under the umbrella of the ERAEDTA Registry's QUality European STudies (QUEST) initiative [7]. Within QUEST the standardization of clinical performance indicators has received great attention. Clinical experts from many European countries have been invited to participate in four clinical working groups on anaemia, calcium-phosphate metabolism, cardiovascular risk and dialysis adequacy. These working groups have produced a draft list of standardized clinical performance indicators including a priority for data collection. This draft list will now need the input of national registry committees and boards of the national societies of nephrology before it can be transformed into a final list of indicators for collection by renal registries.

\section{KARGER}

Fax +4161306 1234

E-Mail karger@karger.ch

www.karger.com (c) 2007 S. Karger AG, Basel

0253-5068/07/0253-0219\$23.50/0

Accessible online at:

www.karger.com/bpu
Kitty J. Jager, MD, PhD

ERA-EDTA Registry, Academic Medical Center

Department of Medical Informatics, J1b 115.1

PO Box 22700, NL-1100 DE Amsterdam (The Netherlands)

Tel. +31 20566 7645, Fax +31 20691 9840, E-Mail k.j.jager@amc.uva.nl 
Along the same lines, action has been taken to try and solve the problem of data collection itself. Given the additional working burden for centres and the fear of incomplete data returns, many registries have long hesitated to extend their data collection. After all, the data collection in most European countries is still voluntary and not linked to the reimbursement of RRT. However, many found the example of the UK Renal Registry that uses data extraction from hospital records worth following. The enormous variety of electronic patient management systems used in dialysis centres across Europe has led the QUEST data extraction working group to also take a standardized approach in this matter. The group adopted the Health Level 7 (HL7) version 3, which is an international standard for the exchange, management and integration of electronic healthcare information, to be instrumental in the data extraction process. To our expectations, it will take at least a few years before automated data extraction from electronic patient data management systems using HL7 will become a reality.

We are confident, however, that a standardized 'European' approach with room for some subsequent adaptation at the local level will contribute to the realization of a dream in which the majority of nephrologists in Europe receive the information they need to improve the quality of RRT care.

\section{References}

1 Richards N, Ayala JA, Cesare S, Chazot C, Di Benedetto A, Gassia JP, Merello JI, Rentero R, Scatizzi L, Marcelli D: Assessment of quality guidelines implementation using a continuous quality improvement programme. Blood Purif 2007;25:221-228.

2 European Best Practice Guidelines for Hemodialysis (Part 1). Nephrol Dial Transplant 2002;17(suppl 7).

3 European Best Practice Guidelines for the Management of Anemia in Patients with Chronic Renal Failure. Nephrol Dial Transpl 1999;14(suppl 5).
4 Steil H, Amato C, Carioni C, Kirchgessner J, Marcelli D, Mitteregger A, Moscardo V, Orlandini G, Gatti E: EuCliD ${ }^{\circledR}$ - a medical registry. Methods Inf Med 2004;43:83-88.

5 Hegbrant J, Alper A, Bosch JP: Practical approach to data collection in a European dialysis network. Contrib Nephrol. Basel, Karger, 2002, vol 137, pp 287-292.

6 Ansell D, Feest T (eds): UK Renal Registry Report 2004. Bristol, UK Renal Registry, 2004.

7 Jager KJ, Zoccali C: QUality European STudies (QUEST) - a step forward in the quality of RRT care. Nephrol Dial Transplant 2005; 20:2005-2006. 